\title{
An enthalpy-based finite element method for solving two-phase Stefan problem
}

\author{
D. Tarwidi \\ School of Computing, Telkom University \\ Jalan Telekomunikasi No. 1 Terusan Buah Batu, Bandung 40257, Indonesia \\ dedetarwidi@telkomuniversity.ac.id
}

\begin{abstract}
Stefan problem is a problem involving phase transition from solid to liquid or vice versa where boundary between solid and liquid regions moves as function of time. This paper presents numerical solution of one-dimensional two-phase Stefan problem by using finite element method. The governing equations involved in Stefan problem consist of heat conduction equation for solid and liquid regions, and also transition equation in interface position (moving boundary). The equations are difficult to solve by ordinary numerical method because of the presence of moving boundary. As consequence, the equations is reformulated into the form of internal energy (enthalpy). By the enthalpy formulation, solution of the heat conduction equations is no longer concerning the phase state of material. The advantage of the enthalpy formulation is that, finite element method can be easily implemented to solve Stefan problem. Numerical simulation of interface position, temperature profile, and temperature history has good agreement with the exact solution. The approximation of interface position using finite element method is found that it is more accurate than the approximation by using Godunov method. The simulation results reveal that finite element method has mean absolute error of 0.000002 while Godunov method has mean absolute error of 0.000075 .
\end{abstract}

Keywords: Stefan problem, finite element method, enthalpy formulation, moving boundary

\begin{abstract}
Abstrak
Stefan problem adalah masalah yang melibatkan transisi fase dari padat ke cair atau sebaliknya dimana batas antara daerah padat dan cair bergerak sebagai fungsi dari waktu. Makalah ini menyajikan solusi numerik dari Stefan problem satu dimensi dua fase dengan menggunakan metode elemen hingga. Persamaan pengatur yang terlibat dalam Stefan problem terdiri dari persamaan konduksi panas untuk daerah padat dan cair, dan juga persamaan transisi pada posisi interface (batas bergerak). Persamaan-persamaan ini sulit dipecahkan dengan metode numerik biasa karena adanya batas bergerak. Sebagai konsekuensinya, persamaan-persamaan tersebut direformulasikan menjadi bentuk energi internal (entalpi). Dengan formulasi entalpi, solusi dari persamaan konduksi panas tidak lagi memperhitungkan keadaan fase dari material. Keuntungan dari formulasi entalpi ini adalah metode elemen hingga dapat dengan mudah diimplementasikan untuk memecahkan Stefan problem. Simulasi numerik untuk posisi interface, profil temperatur, dan histori temperatur memiliki kecocokan yang cukup dekat dengan solusi eksak. Aproksimasi posisi interface menggunakan metode elemen hingga lebih akurat dibandingkan dengan aproksimasi menggunakan metode Godunov. Hasil simulasi menunjukkan bahwa metode elemen hingga memiliki eror absolut rata-rata sekitar 0.000002 sedangkan metode Godunov memiliki eror absolut rata-rata sekitar 0.000075 .
\end{abstract}

Kata Kunci: Stefan problem, metode elemen hingga, formulasi entalpi, batas bergerak

\section{INTRODUCTION}

TEFAN problem is a problem related to phase change, from solid to liquid (melting) or from liquid to solid (solidification), where the boundary between the solid and liquid regions moves as function 
of time. The governing equations involved in the Stefan problem are heat conduction equations for the solid and liquid regions, and an equation connecting solid and liquid regions which is called a moving boundary. The essence of solving Stefan problem is to find solutions of heat conduction equations for solid and liquid regions and also the moving boundary. Solving the heat conduction equation is not really difficult, but when the boundary is moving, the solution of the heat conduction equations becomes complicated. The presence of moving boundary is main characteristic of the Stefan problem and is part of the solution.

Stefan problem has been known since physics scientist Josef Stefan simulated the melting of polar ice cap in 1890 and compared the results of his simulations with observational data. Currently, Stefan problem has become the object of research and development in various applications of science and engineering, industry, and medical science. In engineering, Stefan problem must be solved in modeling of solar cooker with heat storage using phase change material [12]. In other industrial applications, Stefan problems are often encountered in the process of food freezing, melting/solidification of metals, and production of ice [8]. In the field of medical science, Stefan problem also arises in cryosurgery problem, i.e. unwanted tissue destruction technique by using extremely cold temperatures around $-196^{\circ} \mathrm{C}$ [11].

Many researchers have developed solutions of Stefan problem both analytically and numerically. However, analytical solution of Stefan problem is complicated and very limited in certain cases even for one-dimensional problems. Several methods to obtain analytical solution of Stefan problem are quasistationary approximation, pertubation, Megerlin, and heat-balance-integral method [1]. In contrast, numerical solution of Stefan problem is more developed. Based on the existence of grid/mesh, numerical method to find the solution of Stefan problem can be divided into grid/mesh based and without grid/mesh. Grid/mesh based numerical methods are finite difference method [6], [9], [14], finite volume method [5], [17], and finite element method [2], [3], [18]. In general, for simple domain, these three methods are easily implemented to solve Sefan problem. The smoothed particle hydrodynamics (SPH) is a meshless numerical method which can be developed to solve Stefan problem [7]. However, the SPH method has longer computation time compared to mesh based method. This is because SPH method requires even a million of particles to obtain a high order of accuracy.

The finite difference method is a numerical method for solving differential equations based on Taylor's approach. The advantage of finite difference method is that it has faster computation time. But, unfortunately it is difficult to implement for irregular domains. In contrast, numerical schemes for finite volume and finite element method are derived based on the integral form of differential equation. The advantage of these two methods is that they can be implemented for irregular domains and the resulting errors can be minimized. The finite volume method with Godunov scheme to solve two-phase Stefan problem has been comprehensively discussed in [13]. This paper focuses on numerical solution of onedimensional two-phase Stefan problem using finite element method. To overcome the moving boundary, the heat conduction equations for solid and liquid regions will be reformulated into an enthalpy equation [4], [15], [16]. The enthalpy equation is then transformed into an integral form before the finite element method is implemented.

This paper is organized as follows. Section 2 briefly presents Stefan problem and its analytical solutions. The enthalpy formulation and finite element method are discussed in Section 3. Moreover, Section 4 discusses numerical solution for Stefan problem by using finite element method. Then, the finite element solution is compared to analytical solution and Godunov method which has been developed in [13].

\section{Stefan Problem}

\section{A. Physical Formulation}

Suppose there is a container which can be considered as one dimension with length $l$. The container is full of liquid with freezing point $T_{m}$. At initial, the liquid has temperature of $T_{L}>T_{m}$. Moreover, for $t>0$, on the left of the container $(x=0)$, the liquid is given constant temperature $T_{S}<T_{m}$ while on the right of the container $(x=l)$ is no heat transfered out (insulated). As a result, solidification process will occur from left to right of the container. This solidification process will divide the container (domain) 
into two regions: solid and liquid which are separated by an interface (mushy region). Mushy zone can be defined as a region in which solid and liquid phase co-exist. Here, the interface is assumed to be a very thin region. The interface always moves as the solidification takes place. This process is called the two-phase Stefan problem. The solution of the Stefan problem is to determine temperature distribution in the solid and liquid regions and also interface position. In this case, the density of the liquid $\rho$ is assumed constant. The parameters involved in Stefan problem are latent heat: $L$, specific heat of solid and liquid: $c_{L}$ and $c_{S}$, thermal conductivity of solid and liquid: $k_{L}$ and $k_{S}$.

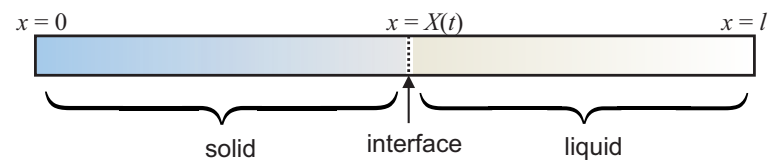

Gambar 1. Illustration of one-dimensional Stefan problem.

Let $X(t)$ be the interface position that separates solid and liquid region at time $t$. Then, $0 \leq x<X(t)$ and $X(t)<x \leq l$ are solid and liquid region, respectively, see Fig. 1 for an illustration of one-dimensional Stefan problem. Furthermore, temperature profile $T(x, t)$ for the solid and liquid regions and also interface position $X(t)$ should be determined. The heat conduction equations for solid and liquid regions can be written respectively as follows

$$
\rho c_{S} \frac{\partial T}{\partial t}=k_{S} \frac{\partial^{2} T}{\partial x^{2}}, \quad 0<x<X(t), \quad t>0 \quad \text { (solid) }
$$

and

$$
\rho c_{L} \frac{\partial T}{\partial t}=k_{L} \frac{\partial^{2} T}{\partial x^{2}}, \quad X(t)<x<l, \quad t>0 \quad \text { (liquid) }
$$

At interface position, based on heat flux equilibrium, the transition equation is expressed as

$$
\rho L \frac{d X(t)}{d t}=k_{S} \frac{\partial T}{\partial x}\left(X(t)^{-}, t\right)-k_{L} \frac{\partial T}{\partial x}\left(X(t)^{+}, t\right), \quad t>0
$$

with temperature at interface position is given by

$$
T(X(t), t)=T_{m}, \quad t>0 .
$$

Besides, initial and boundary conditions may be expressed as

$$
\begin{aligned}
T(x, 0) & =T_{L}>T_{m}, \quad 0<x \leq l, \quad X(0)=0, \\
T(0, t) & =T_{S}<T_{m}, \quad \frac{d T}{d x}(l, t)=0, \quad t>0 .
\end{aligned}
$$

\section{B. Analytical Solution}

The analytical solution of the Stefan problem for finite domain $0 \leq x \leq l$ is very difficult to solve. However, analytical solution for semi-infinite domain $(x \geq 0)$ can be solved and is given by [13]:

$$
T(x, t)=\left\{\begin{array}{l}
T_{S}+\left(T_{m}-T_{S}\right) \frac{\operatorname{erf}\left(\frac{x}{\sqrt{2 \alpha_{\mathrm{S}} \mathrm{t}}}\right)}{\operatorname{erf}(\lambda)}, \quad 0<x<X(t), \quad t>0 \\
T_{L}-\left(T_{L}-T_{m}\right) \frac{\operatorname{erfc}\left(\frac{x}{\sqrt{2 \alpha_{\mathrm{L}}}}\right)}{\operatorname{erfc}\left(\lambda \sqrt{\alpha_{\mathrm{S}} / \alpha_{\mathrm{L}}}\right)}, \quad x>X(t), \quad t>0
\end{array}\right.
$$

and

$$
X(t)=2 \lambda \sqrt{\alpha_{S} t}, \quad t>0 .
$$


Here, erf and erfc refers to an error function and complement of error function, respectively. Parameter $\lambda$ is solution of transcendental equation as follows [13]

$$
\frac{S t_{S}}{\exp \left(\lambda^{2}\right) \operatorname{erf}(\lambda)}-\frac{S t_{L}}{\exp \left(\nu^{2} \lambda^{2}\right) \operatorname{erf}(\nu \lambda)}=\lambda \sqrt{\pi}
$$

where

$$
\alpha_{S}=\frac{k_{S}}{\rho c_{S}}, \quad S t_{S}=\frac{c_{S}\left(T_{m}-T_{S}\right)}{L}, \quad S t_{L}=\frac{c_{L}\left(T_{L}-T_{m}\right)}{L}, \quad \nu=\sqrt{\frac{\alpha_{S}}{\alpha_{L}}} .
$$

The transcendental equation can be approximated numerically by using Newton-Raphson method.

\section{Numerical SOLUTION}

\section{A. Enthalpy Formulation}

The equations (1) - (3) are difficult to solve by ordinary numerical method because of the presence of moving boundary. As consequence, the equations is transformed into the form of energy equation (enthalpy). In the form enthalpy, the solid and liquid phase of material are no longer considered, so that the finite element method can be easily implemented. Representation of equations (1) - (3) in the form of energy conservation is

$$
\frac{\partial E}{\partial t}+\frac{\partial q}{\partial x}=0
$$

where $q(x, t)$ is heat flux which is given by Fourier's Law: $q=-k \partial T / \partial x, k=k_{S}$ for solid region, and $k=k_{L}$ for liquid region. Moreover, $E(x, t)$ is enthalpy per unit length in position $x$ at time $t$ and $q(x, t)$ is the heat flux at position $x$ and time $t$. Moreover, The enthalpy $E(x, t)$ is the sum of sensible and latent heat:

$$
E(x, t)=\left\{\begin{array}{lll}
\int_{T_{m}}^{T(x, t)} \rho c_{S}(\tau) \mathrm{d} \tau, & T(x, t)<T_{m} & \text { (solid) } \\
\int_{T_{m}}^{T(x, t)} \rho c_{L}(\tau) \mathrm{d} \tau+\rho L, & T(x, t)>T_{m} & \text { (liquid). }
\end{array}\right.
$$

This transformation is called enthalpy formulation [8]. The advantage of the enthalpy method is the governing equation is still the same regardless the phases state. For $c_{S}$ and $c_{L}$ constant, the equation (12) can be expressed as

$$
E= \begin{cases}\rho c_{S}\left(T-T_{m}\right), & T<T_{m} \\ \rho c_{L}\left(T-T_{m}\right)+\rho L, & T>T_{m}\end{cases}
$$

or it can be written in the term of temperature [1]:

$$
T=\left\{\begin{array}{lc}
T_{m}+\frac{E}{\rho c_{S}}, E \leq 0 & \text { (solid) } \\
T_{m}, 0<E<\rho L & \text { (mushy) } \\
T_{m}+\frac{E-\rho L}{\rho c_{L}}, E \geq \rho L & \text { (liquid). }
\end{array}\right.
$$

The relationship between enthalpy and temperature can be described in Fig. 2.

\section{B. Finite Element Method}

Finite element method begins by transforming the differential equation into the form of an integral equation or referred to as the weak form. More comprehensive discussion about finite element method can be found in [10]. Here, the differential equation in (11) can be written as follows

$$
k \frac{\partial^{2} T}{\partial x^{2}}-\frac{\partial E}{\partial t}=0, \quad 0 \leq x \leq l,
$$




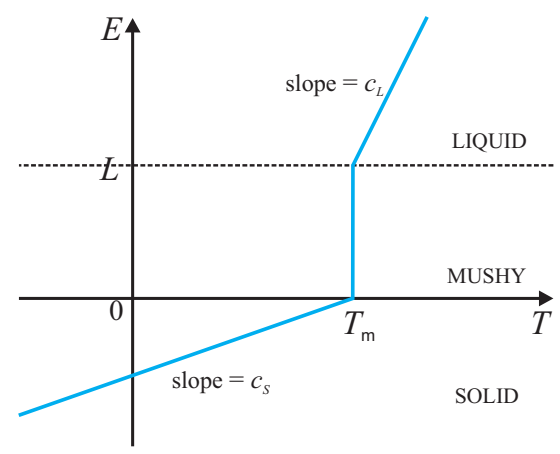

Gambar 2. Relationship between enthalpy and temperature with phase transition solid-liquid or liquid-solid.

Multiply the differential equation in (15) with function $W(x)$, which is called weighting function. Then integrate the left and right hand side of (15) for entire domain $0 \leq x \leq L$ :

$$
-\int_{0}^{L} W(x)\left(k \frac{\partial^{2} T}{\partial x^{2}}-\frac{\partial E}{\partial t}\right) d x=0 .
$$

Equation (16) is multiplied by negative in order to produce an equation that can be easily solved. By using the Chain Rules from Calculus, we have

$$
\frac{\partial}{\partial x}\left(W(x) \frac{\partial T}{\partial x}\right)=W(x) \frac{\partial^{2} T}{\partial x^{2}}+\frac{d W}{d x} \frac{\partial T}{\partial x}
$$

or we can rewrite as

$$
W(x) \frac{\partial^{2} T}{\partial x^{2}}=\frac{\partial}{\partial x}\left(W(x) \frac{\partial T}{\partial x}\right)-\frac{d W}{d x} \frac{\partial T}{\partial x} .
$$

Substitute (17) into (16), it yields

$$
-\int_{0}^{L} \frac{\partial}{\partial x}\left(k W(x) \frac{\partial T}{\partial x}\right) d x+\int_{0}^{L} k \frac{d W}{d x} \frac{\partial T}{\partial x} d x+\int_{0}^{L} W(x) \frac{\partial E}{\partial t} d x=0,
$$

or it can be expressed as

$$
\int_{0}^{L} k \frac{d W}{d x} \frac{\partial T}{\partial x} d x=\left[k W(x) \frac{\partial T}{\partial x}\right]_{x=0}^{x=L}-\int_{0}^{L} W(x) \frac{\partial E}{\partial t} d x .
$$

Equation (18) is called weak form for one-dimensional heat conduction equation.

1) Space Discretization: In discretizing one-dimensional space, without loss of generality, the dependence of variable $T$ in time will be ignored so we just write $T(x)$. One-dimensional linear element is line segment with length of $\Delta x$ and two nodes at the ends, see Fig. 3. The nodes on the left- and right-hand side of an element are symbolized by $X_{i}$ and $X_{j}$ while the temperature values at $X_{i}$ and $X_{j}$ are $T_{i}$ and $T_{j}$, respectively. One-dimensional linear element may be expressed as

$$
T(x)=a_{1}+a_{2} x
$$

Coefficient $a_{1}$ and $a_{2}$ can be determined using conditions at the end nodes of the element, i.e.

$$
\begin{array}{ccc}
T(x)=T_{i} & \text { at } & x=X_{i} \\
T(x)=T_{j} & \text { at } & x=X_{j} .
\end{array}
$$

Moreover, substitute (20) into (19), we write

$$
\begin{gathered}
T_{i}=a_{1}+a_{2} X_{i} \\
T_{j}=a_{1}+a_{2} X_{j} .
\end{gathered}
$$




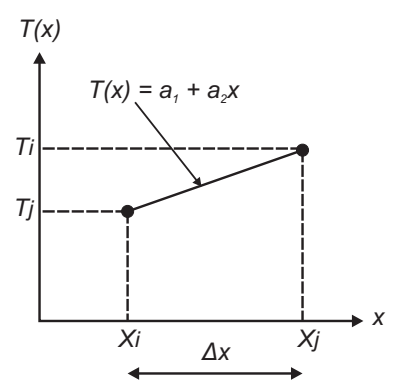

Gambar 3. One-dimensional linear element.

Solve linear equation system in (21) to obtain

$$
\begin{aligned}
& a_{1}=\frac{T_{i} X_{j}-T_{j} X_{i}}{X_{j}-X_{i}} \\
& a_{2}=\frac{T_{j}-T_{i}}{X_{j}-X_{i}} .
\end{aligned}
$$

Finally, substitute (22) into (19), it yields

$$
T(x)=\left(\frac{T_{i} X_{j}-T_{j} X_{i}}{X_{j}-X_{i}}\right)+\left(\frac{T_{j}-T_{i}}{X_{j}-X_{i}}\right) x .
$$

Let $\Delta x=X_{j}-X_{i}$, then rearrange (23),

$$
T(x)=\left(\frac{X_{j}-x}{\Delta x}\right) T_{i}+\left(\frac{x-X_{i}}{\Delta x}\right) T_{j} .
$$

Moreover, we suppose

$$
N_{i}(x)=\frac{X_{j}-x}{\Delta x} \quad \text { dan } \quad N_{j}(x)=\frac{x-X_{i}}{\Delta x} .
$$

In finite element method, $N_{i}$ dan $N_{j}$ refers to shape or interpolation function. Equation (24) is simplified to

$$
T(x)=N_{i} T_{i}+N_{j} T_{j},
$$

or we can write as

$$
T(x)=[N]\{T\}
$$

where $[N]=\left[N_{i} N_{j}\right]$ is row vector of shape function and

$$
\{T\}=\left\{\begin{array}{l}
T_{i} \\
T_{j}
\end{array}\right\}
$$

is column vector containing $T_{i}$ and $T_{j}$.

For $M$ linear elements, equation (26) is given by

$$
T^{(e)}(x)=N_{i}^{(e)} T_{i}+N_{j}^{(e)} T_{j}, \quad \text { where } \quad e=0,1,2, \ldots, M-1
$$

where

$$
N_{i}^{(e)}(x)=\frac{X_{j}-x}{\Delta x} \quad \text { and } \quad N_{j}^{(e)}(x)=\frac{x-X_{i}}{\Delta x} .
$$

By using (29), at $X_{i}$ and $X_{j}$, we have

$$
\begin{aligned}
& N_{i}^{(e)}\left(X_{i}\right)=1, \quad N_{i}^{(e)}\left(X_{j}\right)=0, \\
& N_{j}^{(e)}\left(X_{i}\right)=0, \quad N_{j}^{(e)}\left(X_{j}\right)=1 .
\end{aligned}
$$


2) Galerkin Method: We will use Galerkin Method, which chooses weighting function, $W(x)$, equal to shape function, $N(x)$. Suppose $W_{s}(x)$ is weighting function at node $s$. Moreover, the shape function at node $s$ consists of shape function on the left-hand side of node $s$, i.e. $N_{s}^{(e)}$ and the right-hand side of node $s$, i.e. $N_{s}^{(e+1)}$, see Fig. 4. Based on Galerkin Method, $W_{s}(x)$ is given by

$$
W_{s}(x)=\left\{\begin{array}{lc}
N_{s}^{(e)}, & X_{r} \leq x \leq X_{s} \\
N_{s}^{(e+1)}, & X_{s} \leq x \leq X_{t} \\
0, & \text { others }
\end{array}\right.
$$

By using Galerkin Method, then (18) becomes

$$
\int_{0}^{L} k \frac{d N}{d x} \frac{\partial T}{\partial x} d x=\left[k N(x) \frac{\partial T}{\partial x}\right]_{x=0}^{x=L}-\int_{0}^{L} N(x) \frac{\partial E}{\partial t} d x .
$$

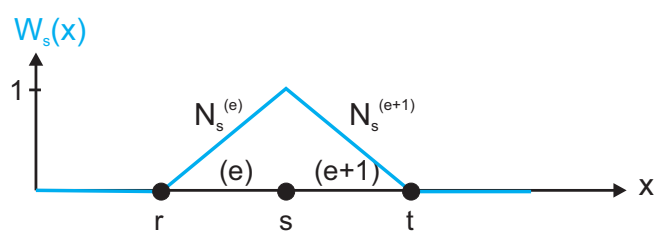

Gambar 4. Weighting function for node $s$.

Let $(e)$ be arbitrary element with $X_{i}$ and $X_{j}$ are node in the left- and right-hand side of the element, respectively. Shape function for element (e) is $N_{i}^{(e)}$ and $N_{j}^{(e)}$. Weighting function for arbitrary element (e) can be illustrated in Fig. 5. Therefore, for arbitrary element (e) and fact that $N_{i}\left(X_{i}\right)=1, N_{i}\left(X_{j}\right)=0$, $N_{j}\left(X_{i}\right)=0, N_{j}\left(X_{j}\right)=1$, then (31) can be written as

$$
\int_{X_{i}}^{X_{j}} k^{(e)} \frac{d N_{i}^{(e)}}{d x} \frac{d T^{(e)}}{d x} d x=-\left.k \frac{d T}{d x}\right|_{x=X_{i}}-\int_{X_{i}}^{X_{j}} N_{i}^{(e)} \frac{\partial E}{\partial t} d x
$$

and

$$
\int_{X_{i}}^{X_{j}} k^{(e)} \frac{d N_{j}^{(e)}}{d x} \frac{d T^{(e)}}{d x} d x=\left.k \frac{d T}{d x}\right|_{x=X_{j}}-\int_{X_{i}}^{X_{j}} N_{j}^{(e)} \frac{\partial E}{\partial t} d x
$$

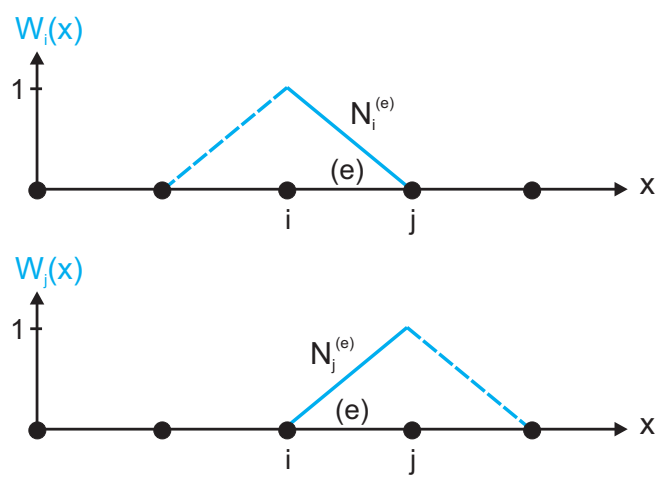

Gambar 5. Weighting function for element $(e)$. 
Based on (28) and (29), derivative of $N_{i}, N_{j}$, and $T^{(e)}$ with respect to $x$ is

$$
\begin{aligned}
\frac{d N_{i}^{(e)}}{d x} & =-\frac{1}{\Delta x} \\
\frac{d N_{j}^{(e)}}{d x} & =\frac{1}{\Delta x} \\
\frac{d T^{(e)}}{d x} & =\frac{1}{\Delta x}\left(-T_{i}+T_{j}\right) .
\end{aligned}
$$

Solve (32) and (33), we obtain

$$
\frac{-k^{(e)}}{\Delta x}\left(-T_{i}+T_{j}\right)=\left.q\right|_{x=X_{i}}-\int_{X_{i}}^{X_{j}} N_{i}^{(e)} \frac{\partial E}{\partial t} d x
$$

and

$$
\frac{k^{(e)}}{\Delta x}\left(-T_{i}+T_{j}\right)=-\left.q\right|_{x=X_{j}}-\int_{X_{i}}^{X_{j}} N_{j}^{(e)} \frac{\partial E}{\partial t} d x .
$$

For solving time dependent problem, we suppose that $\partial E / \partial t$ can be expressed as

$$
\frac{\partial E^{(e)}}{\partial t}=N_{i}^{(e)} \frac{\partial E_{i}}{\partial t}+N_{j}^{(e)} \frac{\partial E_{j}}{\partial t}=N_{i}^{(e)} \dot{E}_{i}+N_{j}^{(e)} \dot{E}_{j}
$$

Substitute (39) into (37) and (38), then solve integral on right-hand side, it yields

$$
\frac{-k^{(e)}}{\Delta x}\left(-T_{i}+T_{j}\right)=\left.q\right|_{x=X_{i}}-\frac{2}{6} \Delta x \dot{E}_{i}-\frac{1}{6} \Delta x \dot{E}_{j}
$$

and

$$
\frac{k^{(e)}}{\Delta x}\left(-T_{i}+T_{j}\right)=-\left.q\right|_{x=X_{j}}-\frac{1}{6} \Delta x \dot{E}_{i}-\frac{2}{6} \Delta x \dot{E}_{j}
$$

or we can write in local (element) matrix as follows

$$
\frac{k^{(e)}}{\Delta x}\left[\begin{array}{cc}
1 & -1 \\
-1 & 1
\end{array}\right]\left\{\begin{array}{l}
T_{i} \\
T_{j}
\end{array}\right\}=\left\{\begin{array}{c}
I_{i} \\
I_{j}
\end{array}\right\}-\frac{\Delta x}{6}\left[\begin{array}{ll}
2 & 1 \\
1 & 2
\end{array}\right]\left\{\begin{array}{c}
\dot{E}_{i} \\
\dot{E}_{j}
\end{array}\right\} .
$$

Therefore, for arbitrary element $(e)$, equation (42) can be written as

$$
\left[c^{(e)}\right]\left\{\dot{E}^{(e)}\right\}+\left[s^{(e)}\right]\left\{T^{(e)}\right\}=\left\{I^{(e)}\right\}
$$

and

$$
\begin{aligned}
{\left[c^{(e)}\right] } & =\frac{\Delta x}{6}\left[\begin{array}{ll}
2 & 1 \\
1 & 2
\end{array}\right] \quad \text { (element mass matrix) } \\
{\left[s^{(e)}\right] } & =\frac{k^{(e)}}{\Delta x}\left[\begin{array}{cc}
1 & -1 \\
-1 & 1
\end{array}\right] \quad \text { (element stiffness matrix) } \\
\left\{\dot{E}^{(e)}\right\} & =\left\{\begin{array}{c}
\dot{E}_{i} \\
\dot{E}_{j}
\end{array}\right\} \\
\left\{T^{(e)}\right\} & =\left\{\begin{array}{c}
T_{i} \\
T_{j}
\end{array}\right\} \\
\left\{I^{(e)}\right\} & =\left\{\begin{array}{c}
I_{i} \\
I_{j}
\end{array}\right\}=\left\{\begin{array}{r}
q_{i} \\
-q_{j}
\end{array}\right\} .
\end{aligned}
$$

Note that $I^{(e)}$ in the interior element will be vanished. Moreover, thermal conductivity $k$ for arbitrary element $(e)$ with left node $i$ and right node $j$ is given by

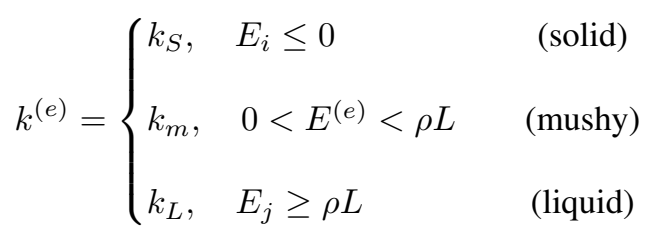


where $k_{m}$ can be approximated by

$$
k_{m}=\left|\frac{E^{(e)}-E^{(e-1)}}{E^{(e+1)}-E^{(e-1)}}\right| k_{S}+\left|\frac{E^{(e+1)}-E^{(e)}}{E^{(e+1)}-E^{(e-1)}}\right| k_{L} .
$$

In equation (45), approximation of $k_{m}$ is obtained by proportionality of solid and liquid fraction in mushy region.

For $M$ number of elements, each element matrix has contribution to form global matrix. Then, global matrix equation can be represented as

$$
[C]\{\dot{E}\}+[K]\{T\}=\{I\},
$$

where $[C]$ and $[K]$ are global mass and stiffness matrix, respectively which are formed by $2 \times 2$ element mass and stiffness matrix. Here, time stepping in the system can be solved by Forward Euler Method as follows

$$
[C]\left\{\frac{E(t+\Delta t)-E(t)}{\Delta t}\right\}+[K]\{T\}=\{I\} .
$$

Let $t^{n}=n \Delta t$, then equation (47) can be written as

$$
[C]\{E\}^{n+1}=[C]\{E\}^{n}+\Delta t\left(\{I\}-[K]\{T\}^{n}\right) .
$$

Equation (48) is a tridiagonal system, so that it will be efficient if it is solved by using Thomas Algorithm. Solution of (48) is enthalpy value at each node, so that to obtain temperature value at each node, we use transformation formula which is given by (14). Finally, temperature profile of Stefan solution is obtained from (14).

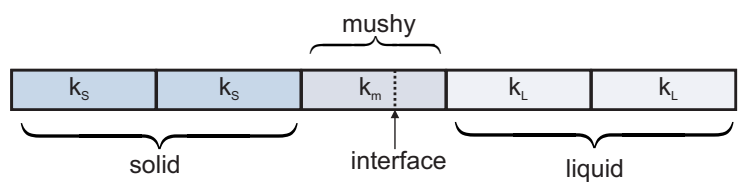

Gambar 6. Interface position in a mushy element.

\section{Interface Tracking}

The interface position $X(t)$ is not always located on the node, but can be located inside an element. Here, the elements in the domain can be divided into three phase categories, i.e. solid, liquid, and mushy elements which are determined by its enthalpy. The position of interface can be ascertained to lie in the mushy element. Inside a mushy element, we need to approximate where the interface position located. Fig. 6 illustrated interface position inside a mushy element.

Suppose $\lambda^{(e)}$ is liquid fraction in an element with $0 \leq \lambda^{(e)} \leq 1$. If $\lambda^{(e)}=0$ then the element contains $100 \%$ of solid, then if $\lambda^{(e)}=0.75$ then the element contains $75 \%$ of liquid and $25 \%$ of solid. The liquid fraction for the element $(e)$ is given by

$$
\lambda^{(e)}= \begin{cases}0, \quad E_{i} \leq 0 & \text { (solid) } \\ \frac{E^{(e)}}{\rho L}, \quad 0<E^{(e)}<\rho L & \text { (mushy) } \\ 1, \quad E_{j} \geq \rho L & \text { (liquid). }\end{cases}
$$

Interface position in mushy element $\left(e_{m}\right)$ at time $t_{n}$ is approximated as

$$
X\left(t_{n}\right)=X_{m}+\left(1-\lambda^{\left(e_{m}\right)}\right) \Delta x,
$$

where $X_{m}$ is node on the left-hand side of mushy element. 

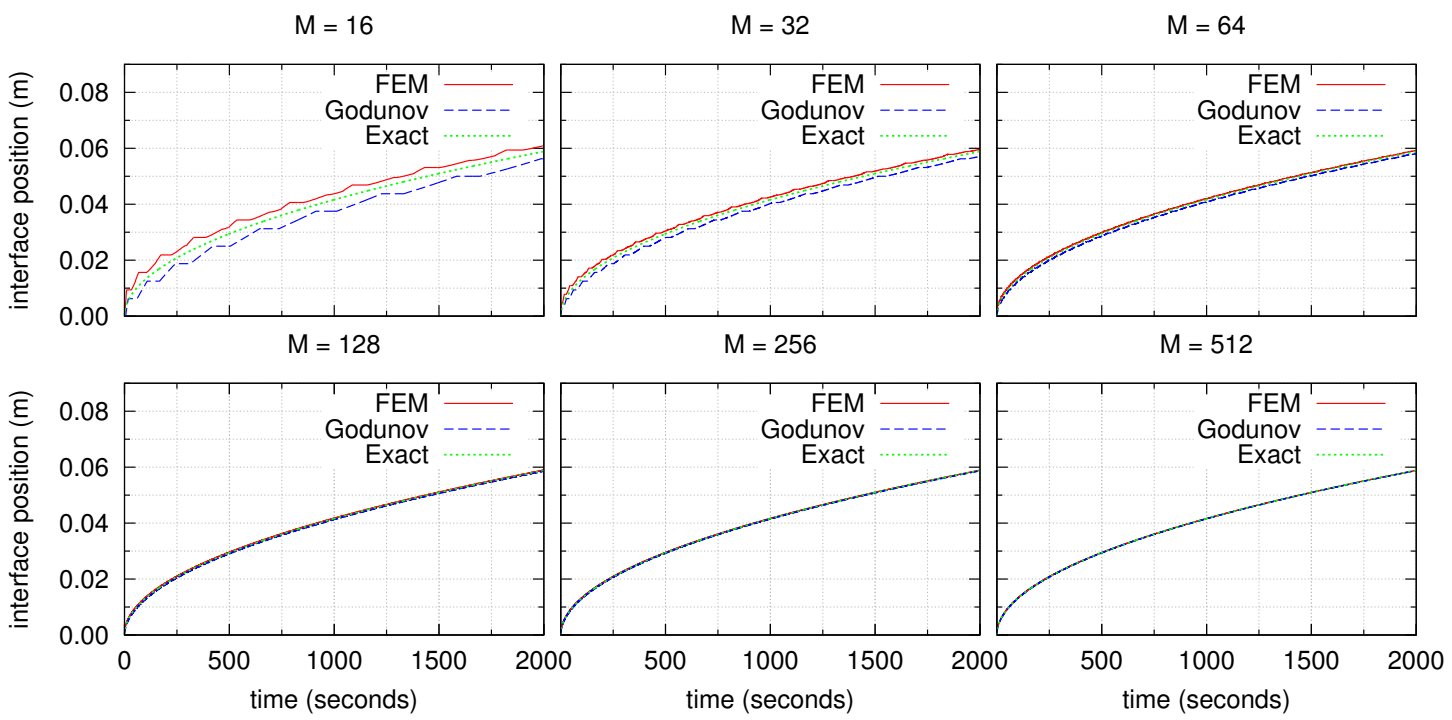

Gambar 7. Interface position for finite element method (FEM) and Godunov method compared to exact solution.
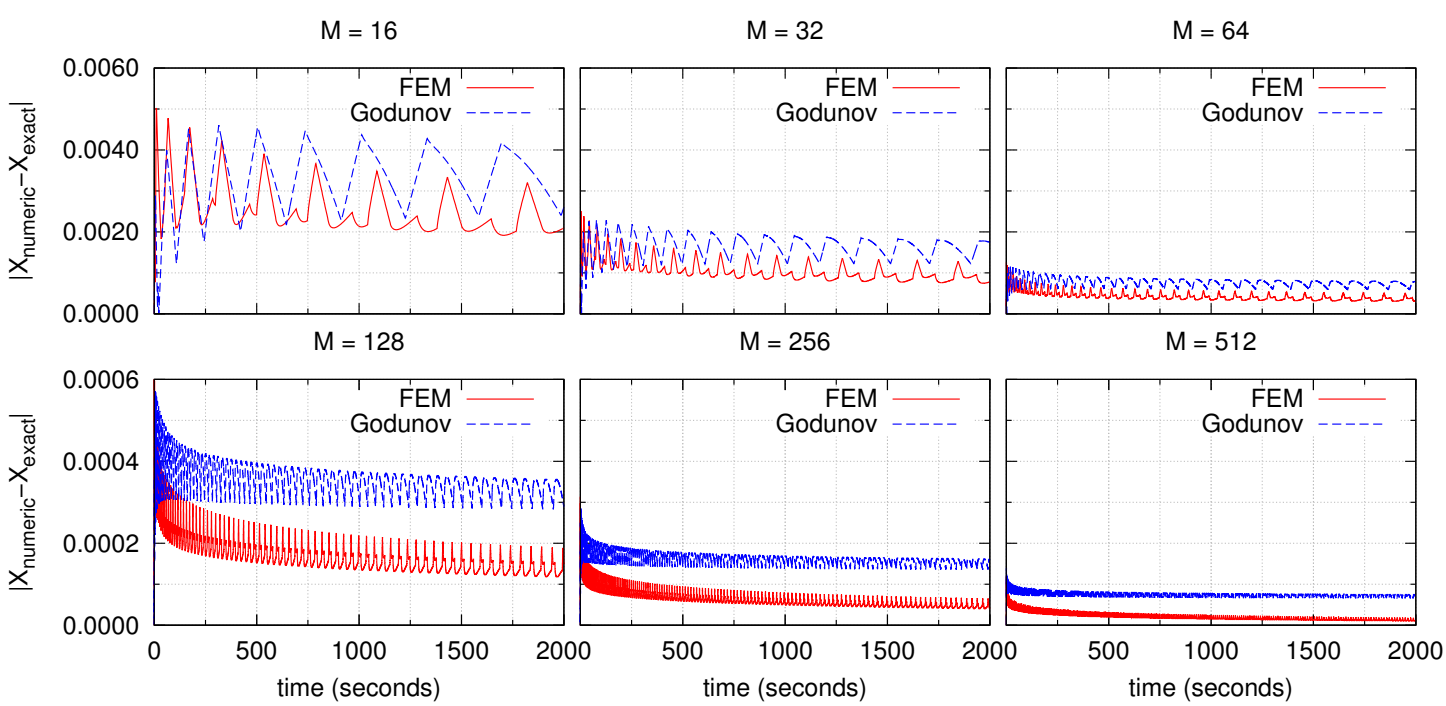

Gambar 8. Absolute error of interface position for finite element method (FEM) and Godunov method.

\section{RESUlts AND Discussion}

We conduct numerical simulation to evaluate accuracy of the finite element method for solving one-dimensional two-phase Stefan problems. We will analyze simulation results for interface position, temperature profile, and temperature history. Suppose the material being simulated is water that occupies a container with length $l=0.1 \mathrm{~m}$. At first, the water is in liquid state with temperature of $T_{L}=37^{\circ}$ C. At $x=0 \mathrm{~m}$, the container is given a constant temperature of $T_{S}=-200^{\circ} \mathrm{C}$ while at $x=0.1$ $\mathrm{m}$ the container is insulated. Other thermophysics parameters are listed in Table I. Numerical results of finite element simulation will be compared with exact solution and also numerical solution by using Godunov method which has been discussed in [13]. In the simulation, we vary the number of elements, i.e. $M=16,32, \ldots, 512$. Particularly, in Godunov method, $M$ refers to the number of control volumes. Here, we assume that the length of each element is uniform, i.e. $\Delta x=l / M$. For the sake of stability, the time step $\Delta t$ is chosen such that the computation is stable and is given by Table II. 

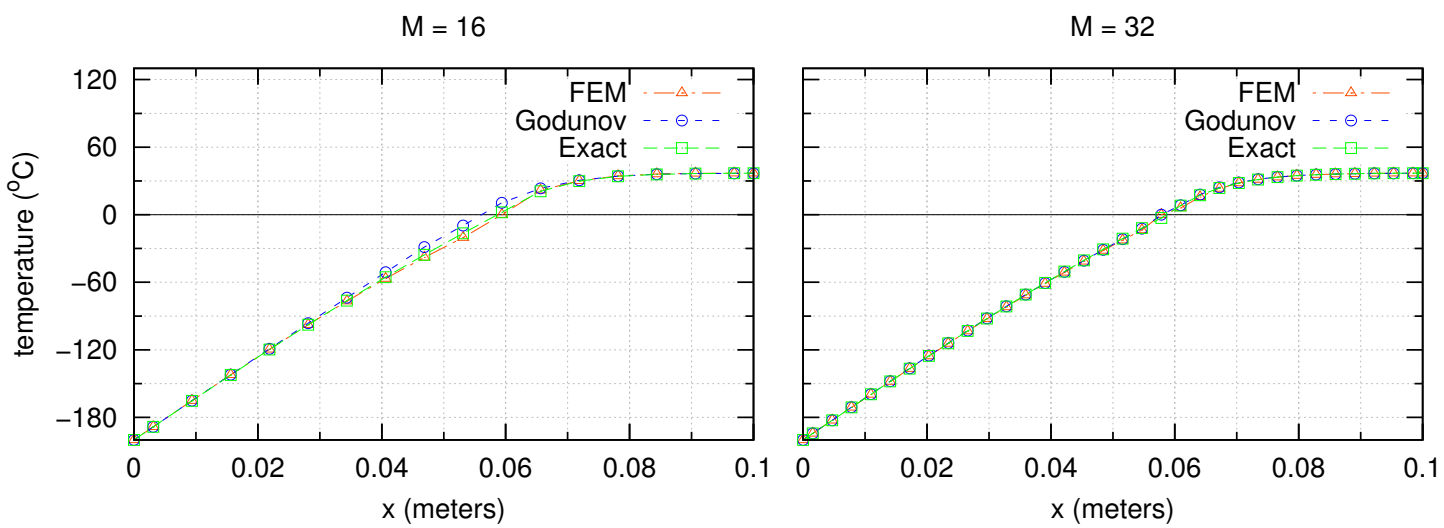

Gambar 9. Temperature profile at $t=2000$ seconds for finite element method (FEM) and Godunov method compared to exact solution.
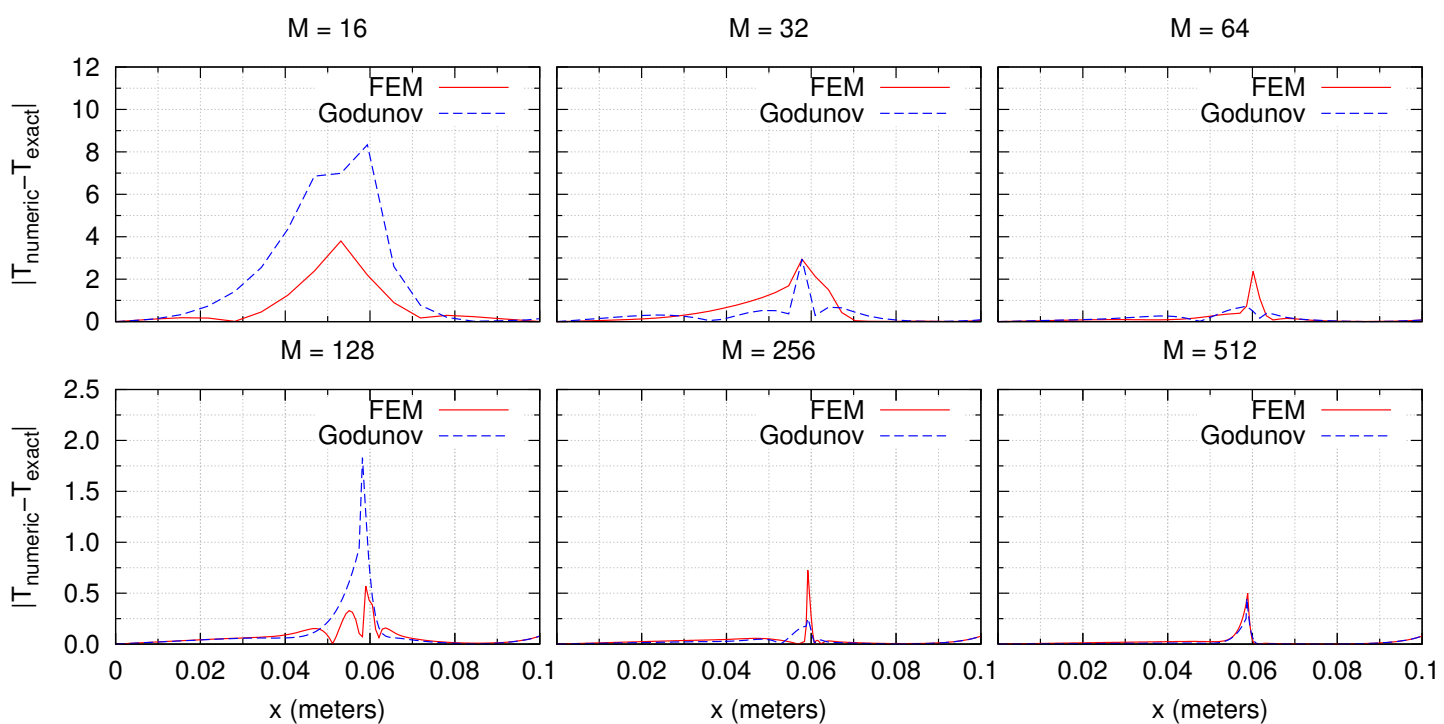

Gambar 10. Absolute error of temperature profile for finite element method (FEM) and Godunov method.

Fig. 7 presents the interface position for $M=16, M=32, M=64, M=128, M=256$ and $M=512$ both finite element and Godunov method. It can be seen that, for $M=16$, numerical solution of the interface position using finite element method overestimates the exact solution, whereas the solution by Godunov method underestimates the exact solution. Based on the figure, it can also be seen that, for many number of elements, finite element method is faster to approach the exact solution than the Godunov method. Moreover, absolute error of interface position for finite element and Godunov method is displayed in Fig. 8. In general, the absolute error of finite element method is always smaller than Godunov method. It reveals that approximation of interface position using (50) is more accurate than approximation by using Godunov method as proposed in [13].

The temperature profile for $M=16$ and $M=32$ is shown in Fig. 9. Based on the figure, it can be seen that both finite element and Godunov method confirms the exact solution. However, around the interface position, absolute error for the temperature profile is quite large compared to temperatures far away from the interface. This is due to in the mushy region, there is temperature jump which is influenced by different thermal conductivity. Fig. 10 depicts absolute error of finite element and Godunov method for temperature profile. Here, for $M=16$ and $M=128$, finite element method has absolute error which is always smaller than Godunov method. Moreover, for $M=64$ and $M=256$ the Godunov method has 

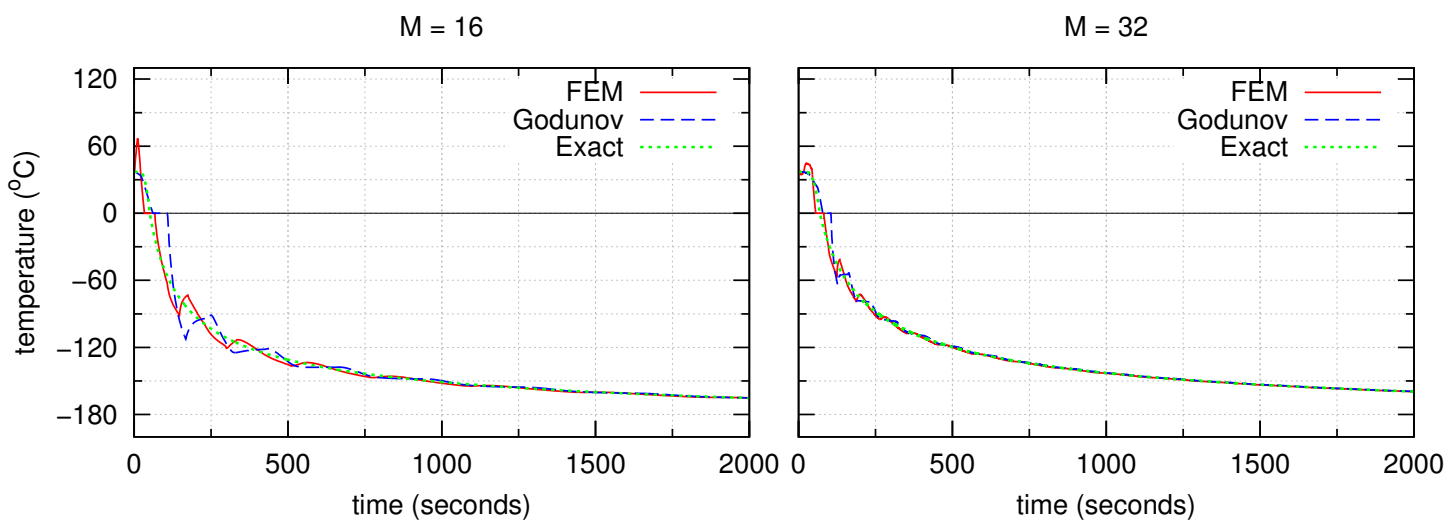

Gambar 11. Temperature history at $x=0.0125 \mathrm{~m}$ for finite element method (FEM) and Godunov method compared to exact solution.

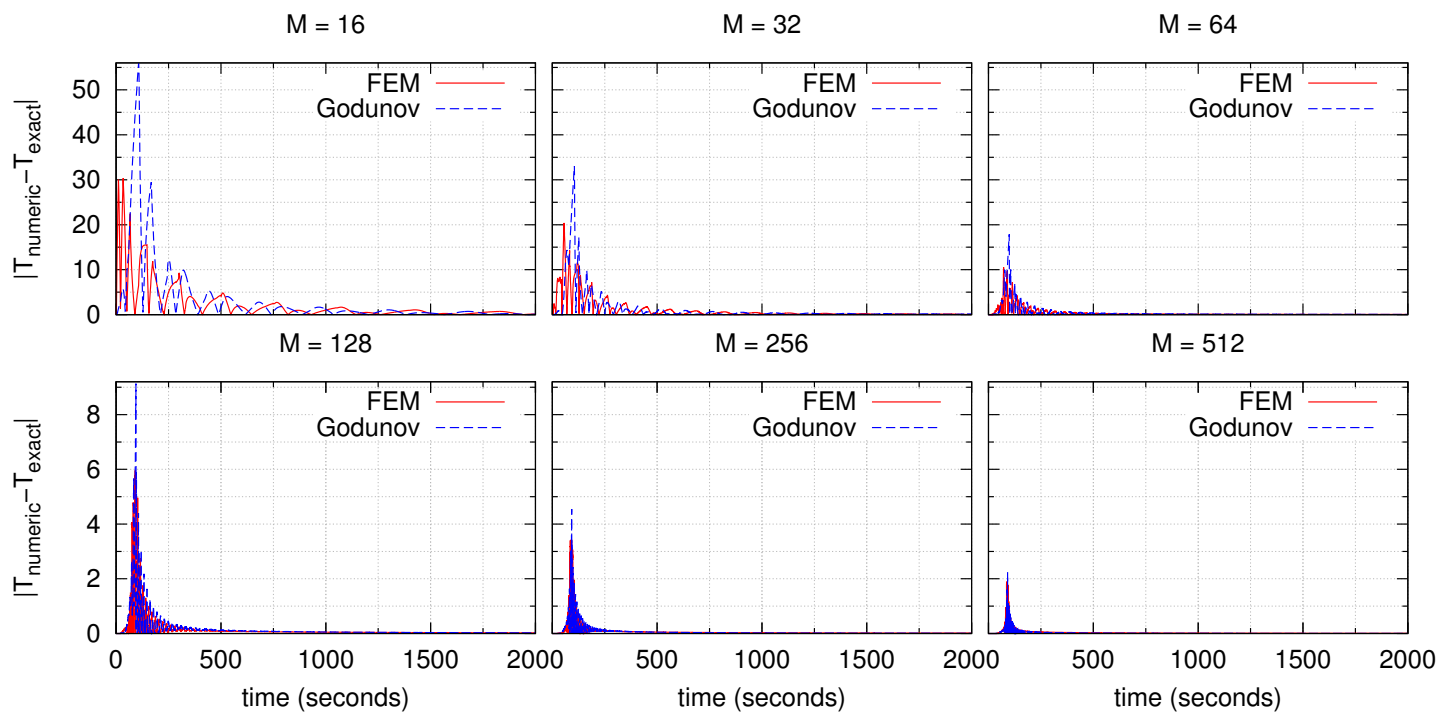

Gambar 12. Absolute error of temperature history at $x=0.0125 \mathrm{~m}$ for finite element method (FEM) and Godunov method.

bigger absolute error than finite element method.

Fig. 11 displays a comparison of numerical solution of finite element and Godunov method for temperature history at $x=0.0125 \mathrm{~m}$ with $M=16$ and $M=32$. As indicated in the figure, it can be seen that temperature history of both finite element and Godunov method is close to the exact solution, except when water temperature is near the freezing point. While absolute error comparison between the finite element and Godunov method is shown in Fig. 12. It can be observed from the figure, absolute error for the finite element and Godunov method decreases as increasing of time. However, in this case, the absolute error for finite element is always smaller than Godunov method.

Table II summarizes maximum error of finite element and Godunov method for interface position, temperature profile, and temperature history. It can be seen that, maximum error of interface position for both finite element and Godunov method decreases with convergence rate about 2.0. However, in this case, the maximum error for the Godunov method is smaller than finite element method. Likewise, for temperature profile, the maximum error of Godunov method is smaller than finite element method, except for $M=16$ and $M=128$. In contrast, for temperature history, the maximum error of finite element method is smaller than the Godunov method, except for $M=512$.

Mean absolute error of finite element and Godunov method for interface position, temperature profile, and temperature history is listed in Table III. It can be seen that, for interface position, mean absolute error 
Tabel I

PHYSICAL PROPERTIES OF WATER [13]

\begin{tabular}{clll}
\hline symbol & parameter & value & unit \\
\hline$c_{s}$ & specific heat of solid & 1.7 & $\mathrm{~kJ} / \mathrm{kg} / \mathrm{K}$ \\
$c_{l}$ & specific heat of liquid & 4.1868 & $\mathrm{~kJ} / \mathrm{kg} / \mathrm{K}$ \\
$k_{s}$ & thermal conductivity of solid & $2.66 \cdot 10^{-3}$ & $\mathrm{~kJ} / \mathrm{m} / \mathrm{s} / \mathrm{K}$ \\
$k_{l}$ & thermal conductivity of liquid & $0.6 \cdot 10^{-3}$ & $\mathrm{~kJ} / \mathrm{m} / \mathrm{s} / \mathrm{K}$ \\
$T_{m}$ & freezing point & 273 & $\mathrm{~K}$ \\
$L$ & latent heat & 333.73 & $\mathrm{~kJ} / \mathrm{kg}$ \\
$\rho$ & density & 1000 & $\mathrm{~kg} / \mathrm{m}^{3}$ \\
\hline
\end{tabular}

Tabel II

MAXIMUM ERROR OF INTERFACE POSITION, TEMPERATURE PROFILE, AND TEMPERATURE HISTORY FOR FINITE ELEMENT METHOD (FEM) AND GODUNOV METHOD.

\begin{tabular}{rcccccrr}
\hline & & \multicolumn{2}{c}{ Interface position } & \multicolumn{2}{c}{ Temperature profile } & \multicolumn{2}{c}{ Temperature history } \\
\hline $\mathrm{M}$ & $\mathrm{dt}$ & FEM & Godunov & FEM & Godunov & \multicolumn{1}{c}{ FEM } & \multicolumn{1}{c}{ Godunov } \\
\hline 16 & 1.6000000 & 0.005024 & 0.004605 & 3.798278 & 8.335126 & 30.327331 & 55.910175 \\
32 & 0.4000000 & 0.002512 & 0.002302 & 2.939151 & 2.939151 & 20.402818 & 33.032380 \\
64 & 0.1000000 & 0.001256 & 0.001151 & 2.368196 & 0.725357 & 10.535077 & 17.863799 \\
128 & 0.0250000 & 0.000628 & 0.000576 & 0.570140 & 1.830244 & 5.964032 & 9.130195 \\
256 & 0.0062500 & 0.000314 & 0.000288 & 0.725537 & 0.252840 & 3.447700 & 4.547238 \\
512 & 0.0015625 & 0.000157 & 0.000144 & 0.499885 & 0.449765 & 2.468223 & 2.237769 \\
\hline
\end{tabular}

Tabel III

MEAN ABSOLUTE ERROR OF INTERFACE POSITION, TEMPERATURE PROFILE, AND TEMPERATURE HISTORY FOR FINITE ELEMENT METHOD (FEM) AND GODUNOV METHOD.

\begin{tabular}{rccccccc}
\hline & & \multicolumn{2}{c}{ Interface position } & \multicolumn{2}{c}{ Temperature profile } & \multicolumn{2}{c}{ Temperature history } \\
\hline $\mathrm{M}$ & $\mathrm{dt}$ & FEM & Godunov & FEM & Godunov & FEM & Godunov \\
\hline 16 & 1.6000000 & 0.002532 & 0.003286 & 0.688276 & 1.976839 & 2.229907 & 3.129111 \\
32 & 0.4000000 & 0.001039 & 0.001635 & 0.464124 & 0.300006 & 0.969988 & 1.098134 \\
64 & 0.1000000 & 0.000422 & 0.000767 & 0.151992 & 0.149143 & 0.337388 & 0.413442 \\
128 & 0.0250000 & 0.000166 & 0.000354 & 0.071411 & 0.113626 & 0.128618 & 0.158097 \\
256 & 0.0062500 & 0.000061 & 0.000162 & 0.031377 & 0.025586 & 0.058326 & 0.058718 \\
512 & 0.0015625 & 0.000002 & 0.000075 & 0.024142 & 0.017056 & 0.028956 & 0.021173 \\
\hline
\end{tabular}

of finite element method is much smaller than Godunov method. It reveals that finite element method has mean absolute error of 0.000002 while Godunov method has mean absolute error of 0.000075 for $M=512$. For finite element method, mean absolute error decreases as the refinement of element with convergence rate varies from 2.4 to 3.1, whereas for Godunov method, the convergence rate is about 2.1. Furthermore, for the temperature profile, Godunov method has smaller mean absolute error than finite element method, except for $M=16$ and $M=128$. Furthermore, for temperature history, finite element method generally has smaller mean absolute error than the Godunov method.

\section{CONCLUSION}

The one-dimensional two-phase Stefan problem has been successfully solved numerically using finite element method via an enthalpy formulation. Numerical results for interface position, temperature profile, and temperature history have been validated with the exact solution and also compared to Godunov method. It has been shown that finite element method has good agreement with the exact solution. The approximation of interface position using finite element has been found that it is more accurate than the approximation by using Godunov method. It has been shown that finite element method has mean absolute error of 0.000002 while Godunov method has mean absolute error of 0.000075 . Suggestion for the future research is to develop finite element method via enthalpy formulation to solve two-dimensional two-phase Stefan problem. 


\section{PUSTAKA}

[1] Vasilios Alexiades. Mathematical modeling of melting and freezing processes. Hemisphere Publishing Corporation, 1981.

[2] NS Asaithambi. A galerkin method for stefan problems. Applied Mathematics and Computation, 52(2-3):239-250, 1992.

[3] G Beckett, John A Mackenzie, and ML Robertson. A moving mesh finite element method for the solution of two-dimensional stefan problems. Journal of Computational Physics, 168(2):500-518, 2001.

[4] Alaattin Esen and Selçuk Kutluay. A numerical solution of the stefan problem with a neumann-type boundary condition by enthalpy method. Applied Mathematics and Computation, 148(2):321-329, 2004.

[5] Chiawen W Lan, Chunchang C Liu, and Chiaming M Hsu. An adaptive finite volume method for incompressible heat flow problems in solidification. Journal of Computational Physics, 178(2):464-497, 2002.

[6] Sarah L Mitchell and M Vynnycky. Finite-difference methods with increased accuracy and correct initialization for onedimensional stefan problems. Applied Mathematics and Computation, 215(4):1609-1621, 2009.

[7] Joseph J Monaghan, Herbert E Huppert, and M Grae Worster. Solidification using smoothed particle hydrodynamics. Journal of Computational Physics, 206(2):684-705, 2005.

[8] SR Pudjaprasetya. Transport phenomena equations and numerical methods. ITB Press, 2018.

[9] Svetislav Savović and James Caldwell. Finite difference solution of one-dimensional stefan problem with periodic boundary conditions. International journal of heat and mass transfer, 46(15):2911-2916, 2003.

[10] Larry J Segerlind. Applied finite element analysis, volume 316. Wiley New York, 1976.

[11] D Tarwidi. Godunov method for computerized lung cancer cryosurgery planning with efficient freezing time. In Information and Communication Technology (ICoICT), 2015 3rd International Conference on, pages 494-499. IEEE, 2015.

[12] D Tarwidi. Modeling and numerical simulation of solar cooker with $\mathrm{pcm}$ as thermal energy storage. In Information and Communication Technology (ICoICT), 2015 3rd International Conference on, pages 584-589. IEEE, 2015.

[13] D Tarwidi and SR Pudjaprasetya. Godunov method for stefan problems with enthalpy formulations. East Asian Journal on Applied Mathematics, 3(2):107-119, 2013.

[14] Fedor Pavlovich Vasil'ev and Aleksandr Borisovich Uspenskii. A difference method for the solution of the two-phase stefan problem. USSR Computational Mathematics and Mathematical Physics, 3(5):1192-1208, 1963.

[15] V Voller and M Cross. Accurate solutions of moving boundary problems using the enthalpy method. International journal of heat and mass transfer, 24(3):545-556, 1981.

[16] VR Voller and L Shadabi. Enthalpy methods for tracking a phase change boundary in two dimensions. International communications in heat and mass transfer, 11(3):239-249, 1984

[17] VR Voller, CR Swaminathan, and Brian G Thomas. Fixed grid techniques for phase change problems: a review. International Journal for Numerical Methods in Engineering, 30(4):875-898, 1990.

[18] Bengt Winzell. Finite element galerkin methods for multi-phase stefan problems. Applied Mathematical Modelling, 7(5):329$344,1983$. 